\title{
As relações de gênero no esporte por discentes da rede pública municipal de Juiz de Fora ${ }^{1}$
}

\author{
Eliete do Carmo Garcia Verbena*
} Elaine Romero **

\begin{abstract}
Resumo: esta pesquisa buscou identificar o significado atribuído ao esporte pelos discentes da Rede Pública Municipal de Juiz de Fora, na ótica do gênero, amparada na teoria das representações sociais. Considerou-se duas dimensões sociais esportivas: esporte-educação e esporte-performance. $\mathrm{O}$ estudo assumiu um caráter qualitativo, utilizando-se da análise do conteúdo, e, acessoriamente, da análise do discurso. O esporte foi representado com valores individualistas, pouco cooperativos, competitivistas, perpetuando estereótipos sexistas. Tal representação relaciona-se com as duas dimensões e evidencia um distanciamento do esporte educacional. Os atores sociais indicam a necessidade de prática esportiva na escola com valores cooperativos, participativos, menos competitivista e não sexista.

Palavras-chave: Esporte, Gênero, Representação Social e Educação Física.
\end{abstract}

A Educação Física é uma área de conhecimento que trabalha com uma gama de conteúdos que envolve a denominada cultura corporal (COLETIVOS DE AUTORES, 1993), resumidos na ginástica, na dança, na luta, nos jogos, na capoeira e no esporte.

Especialmente sobre o esporte, tema central deste estudo, podemos discutir as diversas modalidades, bem como as várias possibilidades de atuação do profissional de Educação Física mediante tal conteúdo. Consideraremos o esporte trabalhado na escola ou esporte educacional e o esporte que visa o rendi-

1 Este artigo é baseado na dissertação de mestrado defendida em dezembro de 2001 na Universidade Castelo Branco e tem como título: "Esporte e gênero: representações entre estudantes da Rede Pública Municipal de Juiz de Fora".

* Mestrado em Ciência da Motricidade Humana - Universidade Castelo Branco (UCB). Professora da Rede Pública Municipal de Juiz de Fora.

** Doutorado na Universidade de São Paulo (USP) e docente do Programa Stricto Sensu - UCB.

Movimento, Porto Alegre, v. 9, n. 2, p. 113-125, maio/agosto de 2003 
mento físico-desportivo, ou seja, esporte-performance ou de rendimento.

A respeito da categoria gênero pela qual serão analisadas as suas relações no esporte, SCOTT (1995) considera as construções culturais e os aspectos sociais das relações entre homem e mulher, transcendendo às análises puramente biológicas. Ao se pensar nas relações de gênero no esporte, deve-se considerar as atitudes de ambos os sexos nessa prática, atitudes que podem possuir diferentes características.

A representação social definida como categorias de pensamento que expressam a realidade, seja para justificá-la ou para questioná-la (MINAYO, 1995), está relacionada com a visão de mundo que as pessoas possuem e são influenciadas pelas suas experiências cotidianas, pelo contexto real. Dessa forma, são construídas historicamente e são sociais porque pertencem a um grupo de indivíduos. A sociedade, por meio do fenômeno esporte, reproduz, constrói e modifica valores diversos, mesmo que de forma inconsciente, numa constante interação social entre os Homens. O entendimento do esporte, associado à questão do gênero, é significativo para melhor compreensão do fenômeno esportivo na construção social e cultural do Homem.

Este estudo, pois, buscou retratar o significado atribuído ao esporte e às relações de gênero, bem como sua aproximação como esporte educacional e de rendimento, com base na teoria das representações sociais. Tais representações foram elaboradas por estudantes da Rede Pública Municipal de Juiz de Fora, especialmente, da Escola Prof ${ }^{a}$ Núbia Pereira Magalhães Gomes.

\section{O esporte e suas relações de gênero}

Atualmente, o esporte é fortemente enfocado em muitas discussões acadêmicas, e também tem conquistado grande espaço na mídia. Algumas modalidades têm crescido no campo da atividade física, seja por influência de ídolos esportivos, seja por estar fortemente presente no cotidiano das pessoas.

ELIAS e DUNNING (1992) percebem haver uma forte integração entre o indivíduo e a sociedade e pressupõem que o esporte tem, na sua evolução e desenvolvimento, relações intrínsecas com a organização e estruturação da sociedade, o que nos

Movimento Porto Alegre, v. 09, n. 2, p. 113-125, maio/agosto de 2003 
permite inferir que modificações sociais determinarão, também, modificações na prática esportiva.

Historicamente, o esporte foi modificado - processo denominado de esportivização - o que fez sobreviver práticas que não gerassem agressões físicas. Nesse caso, os sentimentos das pessoas fluem mais livremente através de estado imaginário que proporciona prazer, excitação e canaliza as emoções. Em razão disso, os praticantes do esporte têm buscado esse tipo de excitação que se apresenta como essencial para a vida do ser humano desde a antigüidade.

A excitação proporcionada pela prática esportiva está presente nas duas dimensões consideradas, porém de forma diferente segundo suas finalidades. Pela educacional, devemos compreender o esporte que é trabalhado no contexto escolar, de cunho eminentemente educativo. Segundo TUBINO (1992), o esporte-educação tem como meta trabalhar valores como cooperação, solidariedade e respeito ao outro, visando a participação incondicional de todos e criando nesses um hábito de vida saudável, o que contribui para melhorar a sua qualidade. É "entendido no processo educacional de formação das pessoas, deve também ser considerado como um caminho essencial para o exercício pleno da cidadania no futuro individual dessas pessoas" (p. 33).

Já o esporte de rendimento é o esporte competitivo, cujo objetivo é o rendimento máximo do atleta. De acordo com TUBINO (op. cit., p. 36), o esporte performance possui "propósitos de novos êxitos esportivos, a vitória sobre adversários...", sendo que, nesse esporte, poucos participam efetivamente e muitos participam passivamente, assistindo aos espetáculos. Essa dimensão esportiva tem como meta o rendimento máximo que culmina com a vitória, sendo valorizados aspectos como a competição, a superação individual ou de equipes. Podemos caracterizá-la como uma prática esportiva antidemocrática, já que a seletividade lhe é inerente.

No esporte, independentemente da dimensão esportiva considerada, as ações podem apresentar diferentes signos e ter diferentes representações aceitas no contexto da sua realização. Por se apresentar como campo para a manifestação da masculinidade, o esporte é considerado revitalizador do sexo. A sociedade cobra determinados padrões de comportamento que são direcionados para o homem e para mulher segundo características socialmente impostas que interferem na prática esportiva.

Movimento, Porto Alegre, v. 9, n. 2, p. 113-125, maio/agosto de 2003 
Assim, construímos e perpetuamos estereótipos que determinam o julgamento que fazemos dos outros e em determinadas circunstâncias, é atribuído um valor diferenciado ao indivíduo por ser ele pertencente ao sexo masculino ou feminino.

Os papéis sexuais tendem a ser definidos antes mesmos de nascermos, contribuindo para posturas diferenciadas e adequadas aos homens e às mulheres, sendo que os valores construídos têm influência do meio em que vivemos, da família a que pertencemos e da educação que nos é oferecida. Para discutir gênero faz-se necessário entendê-lo como algo que vai além da diferença sexual e que considera o aspecto social na relação existente entre homem e mulher. Seguindo o pensamento de SCOTT (1995), o termo gênero

[...] torna-se uma forma de indicar construções culturais - a criação inteiramente social de idéias sobre os papéis adequados aos homens e às mulheres. Trata-se de uma forma de se referir às origens exclusivamente sociais das identidades subjetivas de homens e de mulheres. [...] Gênero é, segundo esta definição, uma categoria social imposta sobre um corpo sexuado [...] palavra particularmente útil, pois oferece um meio de distinguir a prática sexual dos papéis sexuais atribuídos às mulheres e aos homens (p. 75).

Tais papéis, construídos em meio às influências sociais e culturais, provocam a transformação do indivíduo em homem ou mulher e transcendem às considerações em nível físico e biológico.

Refletindo sobre o mesmo assunto, LOURO (1995), BOURDIEU (1995), STUDART (1993) e ROMERO (1997) já nos disseram que, ao longo dos anos, tem sido construída, socialmente, uma imagem diferenciada de homem e mulher. Essa possui uma natureza voltada para a maternidade, para a satisfação sexual do homem e para a imperfeição do organismo, tendo amparo e reforço por meio da influência médica. Esse pensamento, que explica as diferenças entre os sexos pelo aspecto puramente biológico foi desmantelado pelo estudo de AZEVEDO (1997).

Partindo dessas idéias, das finalidades opostas e impostas para o sexo masculino e para o feminino, as crianças são estimuladas a vivências esportivas e brincadeiras cotidianas com características diferenciadas. Normalmente, às meninas são propiciadas atividades que trabalham a coordenação motora fina, reforçando as características de harmonia e delicadeza, o que é evidenciado não só nas modalidades esportivas praticadas pelas

Movimento Porto Alegre, v. 09, n. 2, p. 113-125, maio/agosto de 2003 
meninas (ginástica rítmica, nado sincronizado, etc.), mas em várias situações do cotidiano, nas quais elas se apresentam com mais discrição e menos competitivas. Já os meninos são incentivado à prática de atividades físicas que desenvolvam a coordenação motora ampla, num ambiente em que não é permitido chorar, mesmo havendo a derrota, preparando-os para a disputa, a competição que é refletida em diversas situações cotidianas como no mercado de trabalho. Esses são condicionados a atitudes mais valorizadas, colocando-os em posições superiores que representam mais poder. As experiências distintas proporcionarão práticas esportivas com características diferentes e, conseqüentemente, representações diferentes.

\section{Gênero e esporte: as representações sociais}

Representação significa a compreensão que se tem de algo. MINAYO (1995) afirma que as representações sociais são elaboradas a partir da vivência ou das condições de existência humana, passando a expressar a relação do sujeito com o mundo que lhe é conhecido. Segundo VOTRE (1996, p. 31), "as representações sociais ou individuais fazem com que o mundo seja o que pensamos que ele é ou deve ser". Isto nos permite inferir que nós elaboramos o nosso pensamento de acordo com as nossas escolhas e também por influência de experiências que são priorizadas por alguma classe devido a interesses específicos. De acordo com MOSCOVICI (1978), a representação social "[...] é um "corpus" organizado de conhecimentos e uma das atividades psíquicas graças às quais os homens tornam inteligível a realidade física e social, inserem-se num grupo ou numa ligação cotidiana de trocas, e liberam os poderes de sua imaginação" (p. 28).

As representações sociais assim colocadas são categorias de pensamento de um determinado grupo no qual o Homem se insere. De acordo com JOVCHELOVITCH (1995), quando nós pensamos e falamos em representações sociais, não centramos no sujeito individual, mas nas construções sociais da realidade social. Analisando o esporte sob o aspecto social, Andreu, (apud TUBINO, 1992) identificou que sua vivência é dependente de

usos diferenciados do corpo nas práticas esportivas, as quais são marcadas por representaçôes que induzem modelos de prática, segundo os lugares que se ocupa no espaço das posições sociais e também segundo a imagem dominante dos padrôes feminino e masculino nesta mesma posição social (p. 60).

Movimento, Porto Alegre, v. 9, n. 2, p. 113-125, maio/agosto de 2003 
O uso diferenciado do corpo pelo homem e pela mulher na prática esportiva pode ser verificado em estudos como, por exemplo, o de BRHUNS (2000) e o de VIEIRA (1995 a e b) os quais mostram visões e inserções diferentes de ambos os sexos em modalidades específicas. No primeiro estudo citado (BRHUNS), a mulher é privada de participar da roda de capoeira na sua totalidade, ficando sua atuação limitada ao alcance de determinada hierarquia que normalmente é atingida pelo homem. O estudo de VIEIRA nos mostra que meninos e meninas construíram, socialmente, diferentes visões do esporte. Foi demonstrado um esporte "pra valer", praticado pelos meninos, o qual possui características de competitividade, seriedade para com a vitória e habilidade física. Outro tipo de esporte evidenciado foi denominado de "jogo de mulher", considerado um jogo chato, desmotivante, que não impera a habilidade física e visto com uma "brincadeira". Tais representações denotam que na prática, o esporte é organizado de forma diferente para ambos os sexos, como é visto no futebol e apresentado no estudo de SILVA, COSTA E SALLES (1998).

A questão do gênero no esporte, manifestada pela visão diferenciada em relação aos sexos, é construída em razão do estereótipo atribuído ao mesmos, determinando sua inserção ou exclusão. Estudos como os de ROMERO (1990, 1994 e 1997), DAOLIO (1995) e SOUSA e ALTMANN (1999) explicitam que o sexo feminino, considerado mais fraco e menos habilidoso, é mais excluído da prática esportiva, mas em caso de habilidade feminina e inabilidade masculina o encaminhamento pode ser outro: a inclusão do primeiro e a exclusão do segundo.

Este comportamento ainda é presente na sociedade. Pensar a prática esportiva como direito de ambos os sexos e como vivência não seletiva e não exclusiva urge reflexões acerca da inserção de ambos os sexos, habilidosos ou não, no esporte. Proporcionar essas mudanças exige um compromisso de alargamento dos horizontes e que priorize valores voltados para a vivência do esporte como um direito de todos, incondicionalmente.

\section{Aspectos metodológicos}

Este estudo possui uma abordagem qualitativa, tendo uma amostra composta por 30 indivíduos da Escola Municipal Profa Núbia Pereira Magalhães Gomes, pertencente à Rede Pública

Movimento Porto Alegre, v. 09, n. 2, p. 113-125, maio/agosto de 2003 
Municipal de Juiz de Fora. Estes, com idade compreendida entre 13 e 17 anos, cursavam as $7^{a}$ e $8^{a}$ séries do Ensino Fundamental e todos freqüentavam regularmente as aulas.

O instrumento para a coleta de dados utilizado foi uma entrevista semi-estruturada, gravada em fitas cassete, contendo pontos relacionados às características sociodemográficas dos entrevistados e ao problema a ser estudado.

Para podermos verificar o significado atribuído às relações de gênero no esporte entre estudantes de ambos os sexos, buscou-se apoio teórico nas representações sociais a fim de identificar os valores sociais construídos pelos mesmos a partir de suas vivências.

A fim de investigar a representação do sentido atribuído tanto ao esporte educacional quanto ao esporte de rendimento, o procedimento de análise dos dados adotado foi a análise de conteúdo $(\mathrm{AC})$ e, circunstancialmente, a análise do discurso (AD). Por AC devemos entendê-la como uma técnica que, segundo BARDIN (1977), é

um conjunto de técnicas de análise das comunicações visando obter, através de procedimentos sistemáticos e objetivos de descrição do conteúdo das mensagens, indicadores (quantitativos ou não) que permitam a inferência de conhecimentos relativos às condições de produção/recepção (variáveis inferidas) dessas mensagens (p. 42).

A AD considerada neste estudo analisa o sentido do texto via abordagem sociolingüística e "[...] incide justamente na relação da linguagem com as condições (a situação) em que ela se produz, ou seja, seu contexto sócio-histórico-cultural" (ORLANDI, 1989, p. 11). Nessa perspectiva, as informações serão encaradas como algo objetivo, que contêm conhecimento e não como meras ilustrações ou abstrações. A AD assume um compromisso pragmático da linguagem no seu sentido social e histórico. Nessa perspectiva, a linguagem é entendida como mediação necessária entre o homem e a realidade natural e social, numa perspectiva constitutiva e transformadora e não como mero instrumento, sendo necessário perceber que há "uma relação necessária entre o dizer e as condições de produção desse dizer" (ORLANDI, 1986, p. 109).

\section{Sobre os resultados e as considerações finais}

Pensando nas informações discutidas ao longo desta pesquisa, reforçamos a importância da temática do esporte, fenômeno social, e das relações entre os sexos construídas historicamente.

Movimento, Porto Alegre, v. 9, n. 2, p. 113-125, maio/agosto de 2003 
Em sua proximidade com a vida cotidiana, escolar ou não escolar, são engendradas no meio social representações que não se constróem do nada, mas que partem de conceitos já elaborados pelo indivíduo e também de todas as influências sofridas em sua existência. O esporte é considerado um meio de comunicação social, que explicita determinadas condutas sociais, e as relações de gênero, nesse locus, são manifestações dos valores que norteiam o imaginário. Portanto, são fatores que, se analisados, nos possibilitam compreender a complexidade que envolve as relações entre o esporte e o gênero no contexto social.

A representação social do esporte elaborada por alunos de ambos os sexos da Rede Pública Municipal de Juiz de Fora, pode ser compreendida tendo por base a visão dos entrevistados em relação aos aspectos da participação, da cooperação e da competição durante a prática esportiva.

Sobre a participação, percebemos atitudes com características individualistas (por exemplo: o jogo individual, a necessidade da vitória e do reconhecimento individual, a desunião de grupo, a exclusão de colegas e a seleção dos jogadores) e coletivas (por exemplo: valorização da ação em grupo, divisão de tarefas e a amizade), sendo que a postura permeada de ações individualistas superou a perspectiva coletiva. A cooperação foi manifestada por meio de atitudes de respeito e de união entre os jogadores e pela capacidade de agirem em grupo. O comportamento com desrespeito foi apresentado de forma significativa, demonstrando carência de ações cooperativas durante a prática esportiva, associadas à desunião do grupo e ao descompromisso com o esporte, culminando em agressões físicas e verbais. Já a competição foi demonstrada pela necessidade de competir e de ganhar o jogo ( expressas no jogo sério, competitivo e no desejo de vencer), mesmo que para isso o ser humano passe a ser desconsi-derado ou renegado à sua própria sorte. Também foi apresentada uma visão de supremacia da participação, da necessidade de diversão e respeito, manifestadas pelo desejo do respeito, da amizade, da "brincadeira" e da possibilidade de conhecer outras pessoas e de ampliar os horizontes. A ênfase na competição e na vitória foi marcante em relação à importância dada à participação. Em todos esses aspectos ficou explícito um posicio-namento de crítica em relação à postura apresentada diante do esporte. Nesse caso foi manifestado um ideal de prática esportiva que priorizasse a participação integrada, harmoniosa e

Movimento Porto Alegre, v. 09, n. 2, p. 113-125, maio/agosto de 2003 
com valores voltados para a aprendizagem e a vivência, tendo a vitória como conseqüência desse processo.

A respeito da proximidade ou não do significado atribuído ao esporte nas suas dimensões esportivas educacional e de rendimento, pudemos identificar o seguinte:

A representação, demonstrada pela prática real, de um esporte com características individualistas, não-cooperativo e com a presença exacerbada da competição distancia-se plenamente da dimensão educacional, uma vez que esses valores não são priorizados pela escola. Para essa dimensão esportiva, embora tenha sido colocada a participação como ponto importante para a aprendizagem do esporte, percebemos ser necessário que a competitividade exacerbada ceda lugar para a vivência esportiva prazerosa, participativa e solidária. Essa deve suprimir os preconceitos e a discriminação em relação a todas as diferenças apresentadas, principalmente em relação à mulher, partindo para uma formação mista, e também atribuir aos participantes responsabilidade para com a aprendizagem e com a organização do processo.

Com relação ao esporte de rendimento os dois primeiros aspectos também se distanciam pois, independentemente da meta esportiva, é necessário agir em grupo e ser cooperativo. Já o aspecto competitivo se aproxima desta, pois sua finalidade é competir e buscar a vitória.

O ideal de prática esportiva, permeado de valores cooperativos, não-seletivos, e tendo a competição como conseqüência do processo, aproxima-se plenamente da dimensão educacional, distanciando-se da dimensão de rendimento pelo aspecto da não-seletividade e não ênfase na competitividade.

Sobre as relações de gênero com o esporte, as argumentações apresentadas como a agressividade, a habilidade e inabilidade de um e outro sexo, o descompromisso, o preconceito, a competitividade entre os sexos, os interesses diferenciados e a adequação esportiva para os diferentes sexos demonstraram, com clareza, uma representação estereotipada da relação estabelecida pelo homem e pela mulher com a prática esportiva, relação que foi construída historicamente em meio às tramas socioculturais.

Afirmar que o homem é forte e a mulher é fraca, que ele é agressivo e ela é delicada, que ele é menos responsável e mais habilidoso, que eles possuem interesses diferenciados e que não

Movimento, Porto Alegre, v. 9, n. 2, p. 113-125, maio/agosto de 2003 
podem ou não devem participar de determinadas modalidades esportivas revela uma representação pautada na naturalização de valores socialmente construídos, como nos lembra BOURDIEU (op. cit.), que assim se pronuncia:

é com efeito, através dos corpos socializados, istoé, dos habitus, e das práticas rituais parcialmente retiradas do tempo pela estereotipagem e pela repetição indefinida, que o passado se perpetua na longa duração da mitologia coletiva, relativamente libertada das intermitências da memória individual (p. 135).

Mesmo reconhecendo as dificuldades expostas para o trabalho misto, foi pouco assumida uma visão de adequação esportiva para ambos os sexos. Essa adequação teve respaldo nas características de agressividade e de delicadeza ditas masculinas e femininas respectivamente, sendo os esportes caracterizados como masculinizados, o futebol e o basquete, e o esporte caracterizado como efeminado, a ginástica olímpica. Esses deveriam ser praticados pelo homem e pela mulher, respectivamente. Habilidades diferentes são desenvolvidas de forma tão discrepante para ambos os sexos, porque são diferentemente estimuladas, mas, para esses entrevistados, isto é dado naturalmente, biologicamente e moralmente.

As justificativas da prática esportiva não discriminatória esteve amparada no discurso de direitos e capacidades iguais, da persistência feminina e de uma evolução nos valores sociais, caminhando para o não sexismo e para a justiça social. A participação dependerá do interesse pelo esporte. É possível duvidar. Esse questionamento foi feito, porque a visão de ocupação do espaço esportivo confirma a qualidade de privação e a de expansão, desenvolvidas socialmente pela mulher e pelo homem, respectivamente. Como a mulher poderá participar indiscriminadamente do esporte se, na representação do grupo pesquisado há uma desvalorização feminina e valorização masculina? Sendo assim, a oferta igualitária de esportes para ambos os sexos fica camuflada por uma ideologia machista, que impera no mundo esportivo masculinizado.

Na representação de alguns entrevistados, embora a mídia e a sociedade não trabalhem, efetivamente, a fim de que a valorização e o acesso aos diferentes esportes sejam feitos de forma justa para ambos os sexos, há identificação da escola como espaço para a prática esportiva sem discriminação. Isso demonstra que a escola é um local para a vivência não sexista do esporte e, portanto, um local de oportunidade para um trabalho de

Movimento Porto Alegre, v. 09, n. 2, p. 113-125, maio/agosto de 2003 
reversão do quadro caótico de estereotipagem sexual ou, pelo menos, de intervenção pedagógica que faça despertar a consciência crítica em nossos alunos, que interferirá em sua ação na sociedade. Esperamos ser esse o compromisso político-pedagógico dos profissionais de Educação Física. Como nos ensina ROMERO (1994), é imperativo que o professor reconheça a origem de certas diferenças entre os sexos e não atribua a uma razão biológica e a fatores de origem cultural o desempenho de um e outro sexo [...] evitando assim que a Educação Física continue a serviço da ideologia sexista (p. 232).

\section{Representación de las relaciones de género en el deporte para alumnos de la red pública municipal de Juiz de Fora}

Resúmen: el estudio tuvo como objetivo retratar el significado atribuido al deporte y a las relaciones de género, así como su acercamiento con el deporte educativo y de la renta, en base de la Teoría de las Representaciones Sociales. El abordaje fue de naturaleza cualitativa, teniendo comon la población 30 estudiantes, ambos los sexos, con edad entre 13 y 17 años, de Ensino básico, una escuela de la red pública municipal de Juiz De Fora. El instrumento empleado fue una entrevista de la mitad-structuralized, y pues el análisis de los datos fue utilizado el análisis del contenido y, tambien el análisis del discurso. Los resultados habían señalado los aspectos de la participación, de la cooperación y de la competición durante el deportiva práctico. Fue concluido que en lo referente al deporte educativo la representación demostrada para práctico el verdadero estaba de individualista y de no cooperativo con presencia exacerbada de la competición, el distanciando sí mismo de la dimensión educativa. En el deporte de la renta la representación revelada se viene cerca de su propósito; competición y victoria. En las relaciones de género, las discusiones en la agresividad, la capacidad o de un y otro historicamente del sexo no demuestran una representación del estereotipada construida históricamente en medio las tramas sóciohistóricas y culturales.

Palabras clave: Aspectos de Socioculturales, Deporte, Relaciones de la Clase, Representaciones Sociales, Motricidade.

Movimento, Porto Alegre, v. 9, n. 2, p. 113-125, maio/agosto de 2003 
Representing the gender relations in spor by students of the municipal educational system of Juiz de Fora

Abstract: this research intended to identify the meaning attributed to sport by the students from Juiz de Fora public schools, through the perspective of gender, based on the theory of social representations. It were considered two social dimensions into sport: sporteducation and sport-performance. The study assumed a qualitative feature, using the content analysis and, on some occasions, the discourse analysis. The sport was represented with individualist, and few cooperative values and with emphasis on competition, maintaining sexist stereotype. That representation to mix with two dimensions and evidence that it is moving away from the educational sport. The social actors to show the necessity of a sport practice in school with cooperative, not selective, few competitive and not sexist values.

Keywords: Social Cultural Aspects, Sport, Gender Relations, Social Representations, Kinetics.

\section{Referências}

AZEVEDO, Tania. A mulher na Educação Física e no esporte. In: ROMERO (Org.). Mulheres em movimento. Vitória: EDUFES, 1997, p. 113-135.

BARDIN, Laurence. Análise de conteúdo. Lisboa: Edições 70, 1977.

BOURDIEU, Pierre. A dominação masculina. Educação e Realidade. Porto Alegre, v. 20, n. 2, p. 133-184, jul./dez., 1995.

BRUHNS, Heloisa Turini. Futebol, carnaval e capoeira: entre as gingas do corpo brasileiro. Campinas: Papirus, 2000.

COLETIVO DE AUTORES. Metodologia do ensino de educação física. São PauIo: Cortez, 1993

DAOLIO, Jocimar. A construção cultural do corpo feminino ou o risco de se transformar meninas em "antas". In: ROMERO (Org.). Corpo, mulher e sociedade. Campinas: Papirus, 1995, p. 99-108.

ELIAS Norbert e DUNNING Eric. A busca da excitação. Lisboa: DIFEL, 1992.

JOVCHELOVITCH, Sandra. Vivendo a vida com os outros: intersubjetividade, espaço público e Representações Sociais. In: GUARESCHI e JOVCHELOVITCH (Orgs.). Textos em Representações Sociais. Petrópolis: Vozes, 1995, p. 63-85.

LOURO, Guacira Lopes. Gênero, história e educação: construção e desconstrução. Educação e Realidade. Porto Alegre, v. 20, n. 2, p. 101-132, jul./dez., 1995.

MINAYO, Maria Cecília de Souza. O conceito de representações sociais dentro da sociologia clássica. In: GUARESCHI e JOVCHELOVITCH (Orgs.). Textos em Representações Sociais. Petrópolis: Vozes, 1995, p. 89-111.

Movimento Porto Alegre, v. 09, n. 2, p. 113-125, maio/agosto de 2003 
MOSCOVICl, Serge. A representação social da psicanálise. Rio de Janeiro: ZAHAR EDITORES, 1978.

ORLANDI, Eni Puccinelli. $A$ análise do discurso: algumas observações. DELTA, 1986.

ORLANDI, Eni Puccinelli et al. Vozes e contrastes: discurso na cidade e no campo. São Paulo: Cortez, 1989.

ROMERO, Elaine. Estereótipos masculinos e femininos em professores de Educação Física. São Paulo, 1990. Tese (Doutorado em Ciências), Instituto de Psicologia, Universidade de São Paulo, 407p.

ROMERO, Elaine. Educação Física a serviço da ideologia sexista. Revista Brasileira de Ciências do Esporte. Florianópolis, v. 15, n. 3, p. 226-234, jan., 1994.

ROMERO, Elaine. A mulher no espaço social e esportivo. In: Mulheres em movimento, Vitória: EDUFES, 1997, p. 137-163.

SCOTT, Joan. Gênero: uma categoria útil de análise histórica. Educação e Realidade. Porto Alegre, v. 20, n. 2, p. 71-99, jul./dez., 1995.

SILVA, Maria C. de P. Silva, COSTA, Marta de M. e SALLES, José G. do C. Representação social do futebol feminino na imprensa brasileira. In: VOTRE (Org.) Representação social do esporte e da atividade física: ensaios etnográficos. Brasília: Ministério da Educação e do Desporto / INDESP, 1998, p. 79-94.

SOUSA, Eustáquia Salvadora de; ALTMANN, Helena. Meninos e meninas: expectativas corporais e implicações na educação física escolar. Cadernos CEDES 48 corpo e educação. Campinas: Ed. UNICAMP, 1999, p. 52-68.

STUDART, Heloneida. Mulher: objeto de cama e mesa. $23^{a}$ ed. Petrópolis: Vozes, 1993.

TUBINO, Manoel José Gomes. Dimensões sociais do esporte. São Paulo: Cortez, 1992.

VIEIRA, José Jairo. O esporte contemporâneo e as representações sociais. Texto mímeo, 1995a, 33p. (mimeo ).

VIEIRA, José Jairo. Jogo de mulher e jogo prá valer: um novo padrão das representações de gênero no esporte. Texto mímeo, 1995b, 16p. (mimeo ).

VOTRE, Sebastião (Org.). A representação social da mulher na educação física e no esporte. Rio de Janeiro: Editora Central da Universidade Gama Filho, 1996.

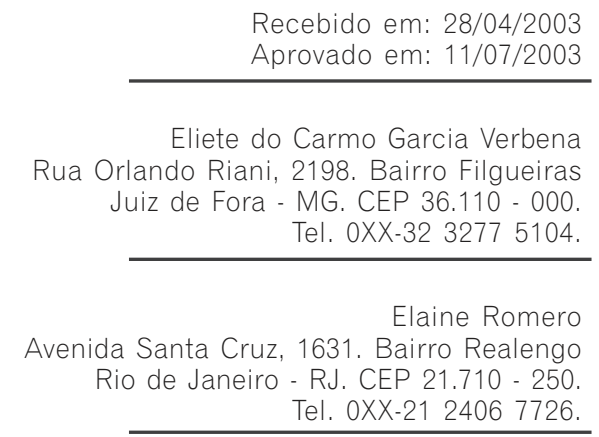

Movimento, Porto Alegre, v. 9, n. 2, p. 113-125, maio/agosto de 2003 